\title{
Technical Note: Particulate reactive oxygen species concentrations and their association with environmental conditions in an urban, subtropical climate
}

\author{
S. S. Khurshid ${ }^{1}$, J. A. Siegel ${ }^{1,2}$, and K. A. Kinney ${ }^{1}$ \\ ${ }^{1}$ Department of Civil, Architectural and Environmental Engineering, The University of Texas at Austin, Austin, Texas, USA \\ ${ }^{2}$ Department of Civil Engineering, The University of Toronto, Toronto, Ontario, Canada
}

Correspondence to: S. S. Khurshid (shahana@utexas.edu)

Received: 30 December 2013 - Published in Atmos. Chem. Phys. Discuss.: 21 February 2014

Revised: 30 April 2014 - Accepted: 25 May 2014 - Published: 3 July 2014

\begin{abstract}
Reactions between hydrocarbons and ozone or hydroxyl radicals lead to the formation of oxidized species, including reactive oxygen species (ROS), and secondary organic aerosol (SOA) in the troposphere. ROS can be carried deep into the lungs by small aerodynamic particles where they can cause oxidative stress and cell damage. While environmental studies have focused on ROS in the gas phase and rainwater, it is also important to determine concentrations of ROS on respirable particles. Samples of $\mathrm{PM}_{2.5}$ collected over $3 \mathrm{~h}$ at midday on 40 days during November 2011 and September 2012 show that the particulate ROS concentration in Austin, Texas, ranged from a minimum value of 0.02 nmoles $\mathrm{H}_{2} \mathrm{O}_{2} \mathrm{~m}^{-3}$ air in December to $3.81 \mathrm{nmoles} \mathrm{H}_{2} \mathrm{O}_{2} \mathrm{~m}^{-3}$ air in September. Results from correlation tests and linear regression analysis on particulate ROS concentrations and environmental conditions (which included ozone and $\mathrm{PM}_{2.5}$ concentrations, temperature, relative humidity, precipitation and solar radiation) indicate that ambient particulate ROS is significantly influenced by the ambient ozone concentration, temperature and incident solar radiation. Particulate ROS concentrations measured in this study were in the range reported by other studies in the US, Taiwan and Singapore. This study is one of the first to assess seasonal variations in particulate ROS concentrations and helps explain the influence of environmental conditions on particulate ROS concentrations.
\end{abstract}

\section{Introduction}

Peroxides are generated in ambient air from alkene ozonolysis and photochemical reactions with volatile organic compounds (VOCs) and $\mathrm{NO}_{\mathrm{x}}$ (Seinfeld and Pandis, 2006). As an example, hydrogen peroxide $\left(\mathrm{H}_{2} \mathrm{O}_{2}\right)$ and hydroperoxyl radical $(\mathrm{HOO} \bullet)$ are produced from the photooxidation of formaldehyde (Bufalini et al., 1972; Gay and Bufalini, 1972; Largiuni et al., 2002). Photochemical models suggest that peroxides can be present in both polluted and clean air (Kleinman, 1986; Heikes et al., 1996), which is confirmed by measurements (Walker et al., 2006; Snow et al., 2007). $\mathrm{H}_{2} \mathrm{O}_{2}$ is an important species in photochemical smog as a chain terminator. Its concentration in rainwater and snow has been measured since the late nineteenth century (Schöne, 1874), and studies have found strong seasonal and diurnal variations in the concentrations of $\mathrm{H}_{2} \mathrm{O}_{2}$ and other reactive oxygen species (ROS) in rainwater, water vapor, and air in gas phase (Singh et al., 1986; Gunz and Hoffman, 1990, and references within; Ayers et al., 1992; Dollard and Davies, 1992; Lee et al., 2000; Yamada et al., 2002; Liu et al., 2003; Zhang et al., 2012). However, data on peroxide and ROS concentrations in the aerosol phase are limited.

It can be suggested that the concentration of peroxides in water associated with atmospheric aerosols can be estimated using gas-phase concentrations of peroxides. Hydroperoxides are thought to partition between the gas phase and liquid water according to their Henry's law constants (e.g., $\mathrm{H}_{\mathrm{H}_{2} \mathrm{O}_{2}}$ is $0.7-1.1 \times 10^{5} \mathrm{M} \mathrm{atm}^{-1}$ at $298 \mathrm{~K}$; Hwang and Dasgupta, 1985; Staffelbach and Kok, 1993; Lind and Kok, 1994; Huang and Chen, 2010). Following this reasoning, 
an ambient gas-phase $\mathrm{H}_{2} \mathrm{O}_{2}$ concentration of $10 \mathrm{ppb}$ would lead to a $1 \mathrm{mM}$ concentration in liquid water associated with aerosols. However, studies on gas-phase ROS have found that urban hydroperoxide levels within aerosols are at least an order of magnitude higher than concentrations predicted by Henry's law (Arellanes et al., 2006; Hasson and Paulson, 2003; Hewitt and Kok, 1991). The Henry's law constant in aerosols may be different from that in liquid water (Hasson and Paulson, 2003), which makes it important to assess the concentration of peroxides and ROS in aerosols.

Reactions between hydrocarbons and ozone or hydroxyl radicals (generated during the photolysis of ozone and in catalytic cycles in the troposphere) lead to the formation of oxidized species and secondary organic aerosol (SOA). Highly soluble gases of oxidized species (such as $\mathrm{H}_{2} \mathrm{O}_{2}$ ) will be removed by the wet mucus lining in the upper airways when they are inhaled (Wexler and Sarangapani, 1998; Sarangapani and Wexler, 2000). However, SOAs are more likely to reach deep into the lungs due to their physical properties, and the ROS associated with these aerosols can, thus, reach the deeper parts of the lung and lead to oxidative stress in the tissue (Morio et al., 2001; Wexler and Sarangapani, 1998). While it would be presumptuous to declare that ROS has a direct toxic mechanism in tissue injury, many in vitro (Oosting et al., 1990; Holm et al., 1991; Geiser et al., 2004; Crim and Longmore, 1995; LaCagnin et al., 1990) and some in vivo studies have drawn links between ROS generated in the body and cell injury, and have also established the involvement of ROS in different pathologies, such as oxygen toxicity disorder (Kehrer, 1993; Sanders et al., 1995; Bowler and Crapo, 2002; Li et al., 2003, 2008). It appears likely that external factors (such as ROS associated with ambient particles) can influence the production of ROS in the body and affect the disease process.

In this study we use a bulk measure to assess the concentration of ROS on ambient particulate matter (PM). 2', 7'dichlorofluorescin diacetate (DCF-DA) is a non-specific fluorescent reagent for detecting ROS, such as hydrogen peroxide $\left(\mathrm{H}_{2} \mathrm{O}_{2}\right)$, and hydroxyl radical $(\bullet \mathrm{OH})$. Ambient concentrations of particulate ROS (Hung and Wang, 2001; Venkatachari et al., 2005, 2007; See et al., 2007) and peroxides in aerosols (Hewitt and Kok, 1991; Hasson and Paulson, 2003; Arellanes et al., 2006; Wang et al., 2010) have been measured previously. However, these studies have been conducted over short periods of time, a few months at most, and do not allow an assessment of seasonal variations in particulate ROS. Ambient particulate matter collected in different seasons has been used in studies to determine the generation of selected oxidative species in lung epithelial cells and surrogate lung fluid (Shen et al., 2011; Vidrio et al., 2009; Baulig et al., 2004). But these seasonal studies generally did not measure the ambient environmental conditions during PM sampling. It is important to understand how the ROS concentration on respirable PM varies as environmental conditions change. Thus, the main objectives of the current study are to (1) de- termine the concentration of ROS on $\mathrm{PM}_{2.5}$ in a semi-arid urban environment over a year, and (2) assess the influence of environmental conditions on these particulate ROS concentrations.

\section{Materials and methods}

Samples of $\mathrm{PM}_{2.5}$ were collected in an open area on the University of Texas at Austin campus using a personal environmental monitor (PEM, SKC, PA, USA) on 40 days between November 2011 and September 2012. Two to five replicate samples were taken on 20 of these days to determine the average covariance in ROS concentration between multiple samplers. Sampling was conducted for $3 \pm 0.5 \mathrm{~h}$ between 10 a.m. and 3 p.m. (Central Standard Time) using air sampling pumps at $10 \mathrm{~L} \mathrm{~min}^{-1}$. Pumps were calibrated before sampling with a mini-Buck Calibrator M-30 (A. P. Buck, Orlando, FL; accuracy $\pm 0.5 \%$ ). Samplers were placed $1 \mathrm{~m}$ above the ground. Teflon tape was wrapped around the edges of the support screen in the PEMs to ensure a proper seal of the thin PTFE filters inside the PEMs. All sampling filters were assessed within $1 \mathrm{~h}$ of collection. This methodology assesses the persistent species in ROS. Highly volatile species are likely to degrade on the order of hours (and may even degrade prior to sample analysis), but the more persistent components of ROS degrade on the order of days - our control studies indicate that the majority of particulate ROS captured on sampling filters remain stable over a day.

DCF-DA has been used as a bulk measure of ROS (Hung and Wang, 2001; Venkatachari et al., 2005, 2007; See et al., 2007) since it becomes fluorescent in the presence of a wide variety of ROS including, but not limited to, hydrogen peroxide $\left(\mathrm{H}_{2} \mathrm{O}_{2}\right)$, organic peroxyl $(\mathrm{ROO} \bullet)$ and hydroxyl $(\bullet \mathrm{OH})$ radicals and the peroxynitrite anion $\left(\mathrm{ONOO}^{-}\right)$( $\mathrm{Zhu}$ et al., 1994; Kooy et al., 1997). The use of a bulk measure enables a better understanding of the overall toxicity potential of the PM. For instance, $\mathrm{H}_{2} \mathrm{O}_{2}$ is generally considered to be less toxic than hydroxyl radicals (Valavanidis et al., 2008), but $\mathrm{H}_{2} \mathrm{O}_{2}$ likely has significant indirect biological effects since it can diffuse across membranes easily because of its lack of charge (LaCagnin et al., 1990). The method for quantifying ROS with DCF-DA was modified slightly from previous studies (Hung and Wang, 2001; Venkatachari et al., 2005, 2007; See et al., 2007) to help reduce high fluorescence intensity of field blanks. The method development is described in detail elsewhere (Khurshid et al., 2014). Briefly, $0.5 \mathrm{~mL}$ of $1 \mathrm{mM}$ DCF-DA (Cayman Chemical, MI, USA) in ethanol was incubated with $2 \mathrm{~mL}$ of $0.01 \mathrm{~N} \mathrm{NaOH}$ at room temperature for $30 \mathrm{~min}$ in the dark to cleave off the acetate groups. The 2',7'-dichlorofluorescin (DCFH) solution was neutralized with $10 \mathrm{~mL}$ sodium phosphate buffer ( $\mathrm{pH} 7.2$ ), and the solution was kept on ice in the dark till needed. Each sampled filter was sonicated in $5 \mathrm{~mL}$ sodium phosphate buffer for $10 \mathrm{~min}$. Horseradish peroxidase (HRP, ThermoScientific, 
IL, USA) in sodium phosphate buffer ( $\mathrm{pH} 7.0)$ was mixed with the DCFH solution and added to the sampled filter in the dark to yield a final volume of $10 \mathrm{~mL}$ with a concentration of $5 \mu \mathrm{M}$ of DCFH and 1 unit $\mathrm{mL}^{-1}$ of HRP. The sample was then incubated in the dark at $37^{\circ} \mathrm{C}$ for $15 \mathrm{~min}$, after which $0.1 \mathrm{~mL}$ aliquots were placed in triplicate in a 96-well plate and the fluorescence intensity was read at $530 \mathrm{~nm}$ with excitation at $485 \mathrm{~nm}$ (Synergy HT, Biotek, VT, USA). The concentration of ROS on the sampled filters was expressed in terms of $\mathrm{H}_{2} \mathrm{O}_{2}$ per volume of air sampled (rather than per mass of particles) because this describes exposure to ROS as it occurs in the lungs (Boogaard et al., 2012). The background fluorescence intensity produced by an unsampled filter was subtracted from the samples.

Standards were prepared with hydrogen peroxide $\left(\mathrm{H}_{2} \mathrm{O}_{2}\right)$. To prepare the standards, aliquots of $0.1 \mathrm{~mL}$ of appropriate $\mathrm{H}_{2} \mathrm{O}_{2}$ concentration were added to $3 \mathrm{~mL}$ of DCFH-HRP reagent to get $0,1.0,2.0,3.0$, and $4.0 \times 10^{-7} \mathrm{M} \mathrm{H}_{2} \mathrm{O}_{2}$ in final solutions. These solutions were incubated at $37^{\circ} \mathrm{C}$ for $15 \mathrm{~min}$, and fluorescence was measured. All glassware used in the experiments was scrubbed with soap, followed by immersion in a $10 \%$ nitric acid bath and subsequent $7 \times$ rinsing with deionized water.

The method detection limit of the analytical procedure, as determined using US EPA's guidelines (EPA, 2011), is 1.2 nmoles $\mathrm{H}_{2} \mathrm{O}_{2} \mathrm{~L}^{-1}$, which converts to 0.01 nmoles m$^{-3}$ assuming a $3 \mathrm{~h}$ sample at $10 \mathrm{~L} \mathrm{~min}^{-1}$. Outliers were excluded using a more conservative approach than the Iglewicz and Hoaglin method (NIST, 2010) in that only sample concentrations with an absolute modified $Z$-score value greater than 10 (instead of 3.5, as recommended by the method) were excluded as outliers. This was done in order to not exclude any real data resulting from variations in outdoor conditions.

Hourly averages of outdoor ozone and $\mathrm{PM}_{2.5}$ concentrations, temperature, solar radiation, and relative humidity (RH) were obtained from the nearest Texas Commission on Environmental Quality's (TCEQ) sampling stations to report the data (located within 7 miles of the ROS sampling site, except for solar radiation which was obtained from a site 17 miles from the sampling site). Global horizontal (GH) solar radiation data were also measured during January-June 2012 on top of a nine-storey building located next to the sampling site using a rotating shadowband radiometer with a data logger (Campbell Scientific, Logan, UT). These GH measurements were taken every minute and averaged over the sampling duration. Daily precipitation data for Austin were obtained from Weather Underground (2013). Overall uncertainty for each measurement was calculated using standard error propagation to include variance in the measured readings and the uncertainty of the instrument when it was known. Graphical representations of the data and ShapiroWilk tests for normality indicated that all the data sets, except for ozone concentration, either followed lognormal distributions or did not follow normal or lognormal distributions. This led to the selection of the non-parametric Spearman

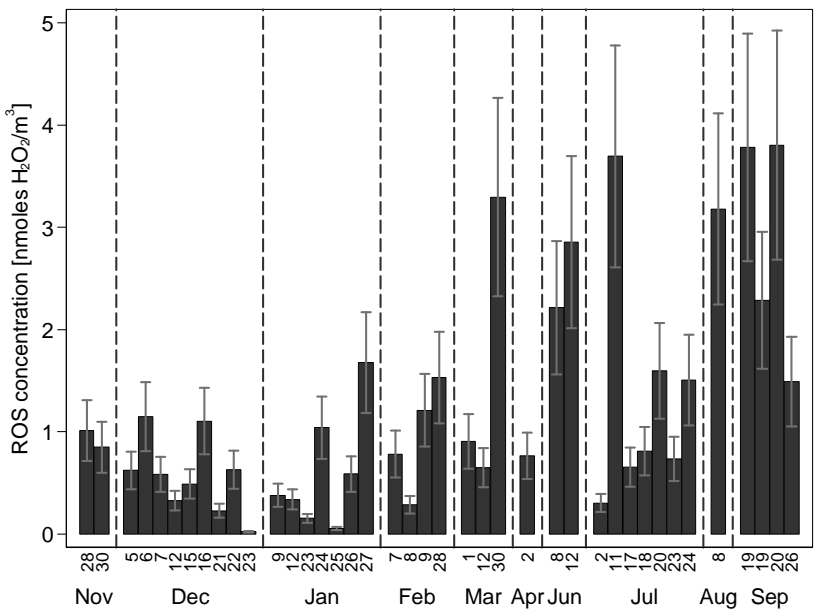

Figure 1. Concentration of ROS on $\mathrm{PM}_{2.5}$ sampled at an outdoor location away from point sources in Austin, Texas. The error bars represent the average standard error of replicate samples taken on 20 of the 40 sampling days.

rank correlation coefficient test to determine the strength $(\rho)$ and significance $(p<0.01)$ of any relationships between the concentration of particulate ROS and environmental factors. Bonferroni correction was applied to these tests. Simple linear regression analysis was also performed between particulate ROS concentrations and each environmental condition measured. All statistics were done with Stata version 11.2.

\section{Results and discussion}

The mean $( \pm \mathrm{SD})$ concentration of ROS on $\mathrm{PM}_{2.5}$ samples collected over $3 \mathrm{~h}$ around midday in Austin, Texas, on 40 days between November 2011 and September 2012 was $1.25 \pm 1.1 \mathrm{nmoles}^{-3}$. The concentrations ranged from 0.02 nmoles $\mathrm{m}^{-3}$ measured on 23 December to $3.81 \mathrm{nmoles} \mathrm{m}^{-3}$ on 20 September. The concentrations on each sampled day are depicted in Fig. 1 with the error bars depicting the average standard error of replicate samples taken on 20 of the 40 sampling days. The sampling site was located away from any point sources, at a distance of about 0.7 miles from an interstate highway. Austin has a transitional, semi-arid climate, characterized by hot summers and mild winters. This is evidenced by the fact that the mean monthly temperature in November-February was $13{ }^{\circ} \mathrm{C}$, whereas during June-September it was $28^{\circ} \mathrm{C}$. Ambient environmental conditions measured at the nearest TCEQ sampling sites during the ROS sampling are given in Supplement Table S1. During the sampling periods on the 40 days, the ozone concentration ranged from 8 to $72 \mathrm{ppb}, \mathrm{PM}_{2.5}$ concentration ranged from 1 to $22 \mu \mathrm{g} \mathrm{m}^{-3}$, temperature ranged from 3 to $35^{\circ} \mathrm{C}$, relative humidity ranged from 21 to $95 \%$, precipitation ranged from 0 to $80 \mathrm{~mm}$, and solar radiation ranged from 23 to $928 \mathrm{~W} \mathrm{~m}^{-2}$. 
Studies have found strong seasonal and diurnal variations in the concentrations of $\mathrm{H}_{2} \mathrm{O}_{2}$ in air, rainwater and water vapor, typically with higher concentrations measured during the summer than the winter (references within Gunz and Hoffman, 1990; references within Sakugawa et al., 1990; references within Lee et al., 2000; Yamada et al., 2002; Liu et al., 2003). However, other studies have found that some ROS species, e.g., peroxyacetyl nitrates $\left(\mathrm{RCO}_{2} \mathrm{ONO}_{2}\right)$ and methyl hydroperoxide $\left(\mathrm{CH}_{3} \mathrm{OOH}\right)$, follow the opposite trend because of greater sensitivity to $\mathrm{NO}_{\mathrm{x}}$ precursor pollutants (Singh et al., 1986; Zhang et al., 2012). In this study, we found that particulate ROS concentrations tend to be higher in the warmer months than in the colder months, implying that particulate ROS follows trends similar to gas-phase and rainwater $\mathrm{H}_{2} \mathrm{O}_{2}$ in the atmosphere.

Table 1 displays the results of the Spearman rank correlation tests between particulate ROS concentrations and measured environmental conditions (ozone and $\mathrm{PM}_{2.5}$ concentrations, temperature, relative humidity, precipitation and solar radiation). The concentration of ROS on $\mathrm{PM}_{2.5}$ was statistically significantly correlated with ozone concentration $(\rho=0.61, p=0.0000)$, temperature $(\rho=0.56, p=0.0002)$ and solar radiation $(\rho=0.61, p=0.0000)$. Several studies have assessed the correlation between particulate ROS concentrations and ozone (Hung and Wang, 2001; Venkatachari et al., 2005, 2007) and also between gas-phase $\mathrm{H}_{2} \mathrm{O}_{2}$ and ozone (Liu et al., 2003). These studies have found moderate correlations between the concentrations of ROS and ozone, with the strongest correlations occurring around midday. Complexities in the chemistry of formation of ROS have been cited as the reason for the relatively moderate correlations with ozone (Venkatachari et al., 2007). Meteorological conditions, such as solar radiation, water vapor concentration, temperature and pressure, are thought to influence the atmospheric concentration of $\mathrm{H}_{2} \mathrm{O}_{2}$ and peroxides (Logan et al., 1981; Jackson and Hewitt, 1999). Only a few studies have assessed the relationship between particulate ROS concentrations and meteorological conditions other than ozone concentration. Venkatachari et al. (2007) had found a weak but statistically significant correlation between particulate ROS and estimated secondary organic carbon concentrations in the atmosphere. Given the evidence for ROS being photochemically driven, one of the objectives of this study was to study the relationship between particulate ROS and certain meteorological conditions that influence photochemical reactions.

The correlations drawn from this data on particulate ROS (between particulate ROS concentrations and ambient air quality parameters) are fairly similar to correlations drawn from studies on gas-phase ROS (between gas-phase ROS $/ \mathrm{H}_{2} \mathrm{O}_{2}$ concentrations and ambient air quality parameters). Yamada et al. (2002) found that gas-phase $\mathrm{H}_{2} \mathrm{O}_{2}$ was positively correlated with solar radiation, UV radiation and temperature, while it was negatively correlated with relative humidity. Liu et al. (2003) found that gas-phase $\mathrm{H}_{2} \mathrm{O}_{2}$ was
Table 1. Spearman's rank correlation coefficients between the concentration of ROS on $\mathrm{PM}_{2.5}$ (ROS), ozone concentration $\left(\mathrm{O}_{3}\right)$, $\mathrm{PM}_{2.5}$ concentration, temperature $(T)$, relative humidity $(\mathrm{RH})$, precipitation (ppt), and solar radiation measured at the nearest TCEQ site (Solar Rad). Significant relationships at $p<0.01$ are in bold and those at $p<0.001$ are further denoted with $*$.

\begin{tabular}{lrrrrrr}
\hline & $\begin{array}{r}\mathrm{ROS} \text { on } \\
\mathrm{PM}_{2.5}\end{array}$ & $\mathrm{O}_{3}$ & $\mathrm{PM}_{2.5}$ & $T$ & $\mathrm{RH}$ & $\mathrm{ppt}$ \\
\hline $\mathbf{O}_{3}$ & $\mathbf{0 . 6 1}^{*}$ & & & & & \\
$\mathbf{P M}_{2.5}$ & 0.27 & 0.03 & & & & \\
$T$ & $\mathbf{0 . 5 6}$ & $\mathbf{0 . 5 2}$ & 0.36 & & & \\
$\mathrm{RH}$ & -0.17 & $\mathbf{- 0 . 5 3}$ & 0.19 & -0.32 & & \\
$\mathrm{ppt}$ & -0.15 & -0.38 & 0.08 & 0.26 & $\mathbf{0 . 5 3}$ & \\
Solar Rad & $\mathbf{0 . 6 1}^{*}$ & $\mathbf{0 . 6 9}^{*}$ & 0.11 & $\mathbf{0 . 7 8}^{*}$ & -0.50 & $-\mathbf{0 . 5 4}$ \\
\hline
\end{tabular}

positively correlated with ozone, and negatively correlated with $\mathrm{NO}_{\mathrm{x}}$. Similar to Liu et al. (2003), we did not find a discernible correlation between ROS and relative humidity. While not significant, the inverse relationship between particulate ROS and daily precipitation could be because of the reduction in gas-phase $\mathrm{H}_{2} \mathrm{O}_{2}$ during rain events (Gunz and Hoffman, 1990), which could lead to reduction in adsorption of gas-phase ROS onto atmospheric aerosols.

The nearest TCEQ sampling site to measure solar radiation was located 17 miles from the ROS sampling site (all other environmental conditions were obtained from TCEQ sites within 7 miles of the ROS sampling site). In order to ensure that the conditions at the ROS sampling site were similar to those at the TCEQ sampling site, solar radiation was measured next to the ROS sampling site during January to June 2012. The solar radiation data from the two sources were seen to match well $(\rho=0.78, p=0.0002)$, and data from the TCEQ site were used for analysis over the entire study period. In addition, other environmental conditions were correlated with each other in ways that were expected. When solar radiation during the sampling event was strong, ozone concentrations and temperatures also tended to be high, as indicated by significant correlations between these parameters. In contrast, solar radiation was lower on days when it rained or had high RH, as indicated by the significant inverse correlations between solar radiation and daily precipitation/RH. Ozone concentrations were also inversely correlated with RH and daily precipitation. Higher temperatures tended to increase the concentration of $\mathrm{PM}_{2.5}$, as indicated by a significant correlation between temperature and $\mathrm{PM}_{2.5}$ concentration, possibly due to an increase in reaction rates leading to SOA formation.

Regression analysis between particulate ROS concentrations and environmental conditions shows that linear regression models between particulate ROS concentrations and ozone concentrations, temperature, and solar radiation are significant $(p<0.001$ for the $F$ test on the model) but with $R^{2}$ values ranging from 0.29 to 0.56 . These regression models are shown in Fig. 2. $t$ tests on the regression 
coefficients for these linear regression models are also significant $(p<0.001)$. A multiple regression model of particulate ROS concentration with ozone concentration, temperature and solar radiation is also significant $(p=0.0000)$ with an $R^{2}$ value of 0.6 , which means that $60 \%$ of the variance of particulate ROS concentrations is accounted for by the model. Standardized coefficients for the multiple regression model are given in the Supplement. It should be noted that the predictor variables (ozone concentration, temperature and solar radiation) for the multiple regression analysis are correlated, which limits the conclusions that can be derived from the model. Linear regression models between particulate ROS concentrations and $\mathrm{PM}_{2.5}$ concentrations, relative humidity and precipitation were not significant and are displayed in Supplement Fig. S1. The regression results indicate that ambient particulate ROS is likely a function of the ambient ozone concentration, temperature and incident solar radiation. Some other contributing factors to particulate ROS concentrations may include ambient particle concentrations and relative humidity, as well as parameters that were not measured in this study, such as the concentration of VOCs, $\mathrm{NO}_{\mathrm{x}}$, hydroxyl and other radical species.

The ROS concentration on $\mathrm{PM}_{2.5}$ reported in the literature ranges from $0.80-0.97$ nmoles $^{-3}$ at a location $14 \mathrm{~km}$ west of Manhattan during winter (Venkatachari et al., 2007), and $4.37-4.98$ nmoles $^{-3}$ close to highway traffic during Los Angeles basin inversion conditions in summer (Venkatachari et al., 2005), to $5.71 \mathrm{nmoles}^{-3}$ in Singapore during December (See et al., 2007). A study in Taiwan reported a concentration of 0.54 nmoles $\mathrm{m}^{-3}$ on $\mathrm{PM}_{3.2}$ on an urban sidewalk during summer (Hung and Wang, 2001). Some other studies use a different analytical method and report ROS concentrations on total suspended particles (TSPs) ranging from $0-0.38$ nmoles m$^{-3}$ in summer in west Los Angeles (Hasson and Paulson, 2003) to $0-0.24$ nmoles $^{-3}$ in summer at $\mathrm{Ni}$ wot Ridge, CO (Hewitt and Kok, 1991). In the present study, we measured ROS concentrations on $\mathrm{PM}_{2.5}$ in the 0.02 $3.81 \mathrm{nmoles} \mathrm{m}^{-3}$ range during November 2011-September 2012 in Austin, Texas. The winter concentrations measured in this study are comparable to winter concentrations measured near Manhattan and summer concentrations in Taiwan. The summer concentrations measured in this study are lower than summer concentrations measured during basin inversion conditions in LA and winter concentrations in Singapore. In comparison, ROS concentrations on TSPs in mainstream cigarette smoke (4-16 $\mu \mathrm{mol} \mathrm{m}^{-3}$ for three different brands of cigarettes; Huang et al., 2005) are 3-4 orders of magnitude higher than all ambient particulate ROS concentrations reported in the literature.

\section{Conclusions}

It is important to measure biologically relevant characteristics of PM to understand the association between PM and
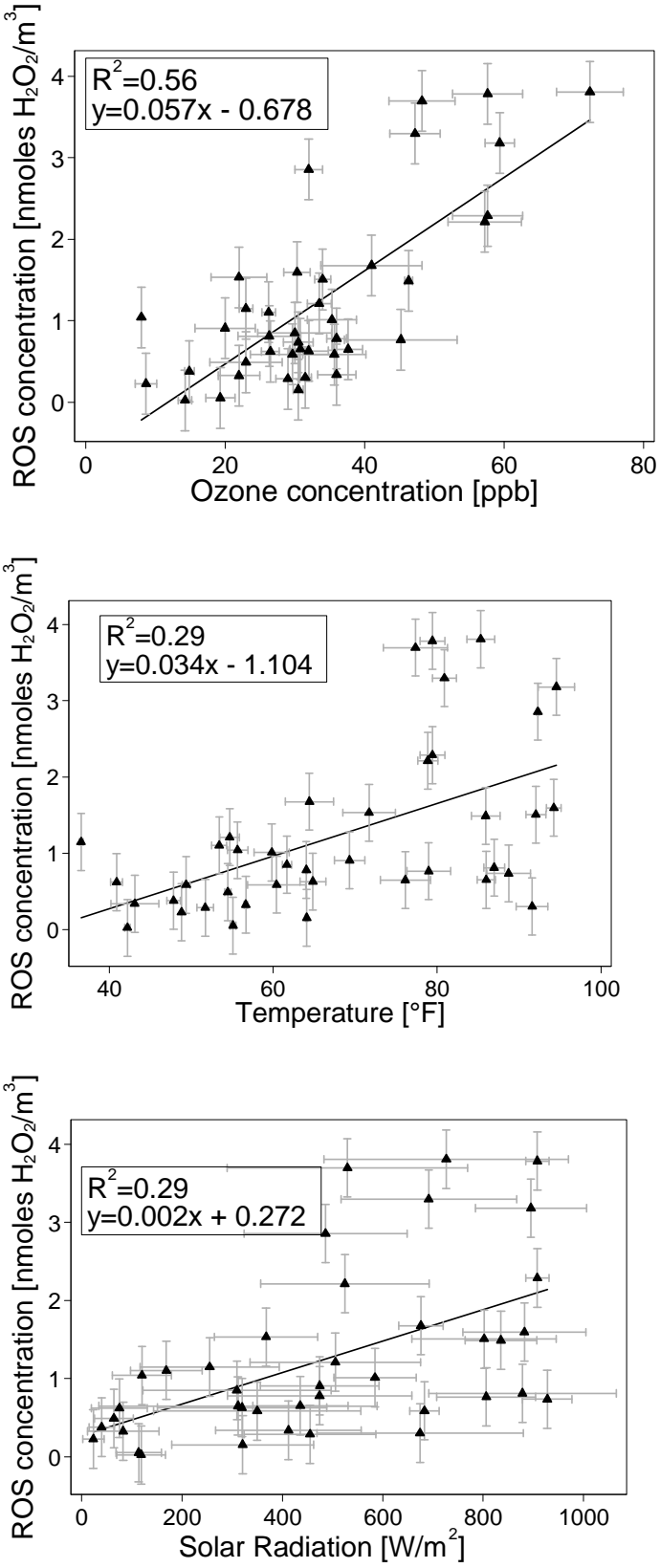

Figure 2. Linear regression graphs showing significant relationships between particulate ROS concentrations and $\mathrm{O}_{3}$ concentration, temperature, and solar radiation. Error bars for ROS concentration represent the average standard error of replicate ROS samples. Error bars for environmental conditions represent the variance in the measurements during the $3 \mathrm{~h}$ sampling period.

adverse health effects including respiratory and cardiovascular illnesses (Samet et al., 2000; Pope III et al., 2002; Bell et al., 2004). In this study, we measured the concentration of ROS associated with $\mathrm{PM}_{2.5}$ in an urban, semi-arid environment over the course of a year. We found that the minimum concentration occurred during the winter while the maximum concentration occurred during the summer, which was 
similar to the results reported in studies on ambient $\mathrm{H}_{2} \mathrm{O}_{2}$ concentrations in gas phase and rainwater. Given that $\mathrm{PM}_{2.5}$ can carry ROS deep into the lungs where the particulate ROS can potentially cause oxidative stress and cell damage, it is important to better understand the environmental conditions that influence the concentrations of ROS on $\mathrm{PM}_{2.5}$. Results from correlation tests and linear regression analysis of particulate ROS concentrations and environmental conditions (which included ozone and $\mathrm{PM}_{2.5}$ concentrations, temperature, relative humidity, precipitation and solar radiation) indicate that ROS associated with ambient particles is significantly influenced by the ambient ozone concentration, temperature and incident solar radiation. Particulate ROS concentrations measured in this study were within the range 0.0-5.7 nmoles $\mathrm{m}^{-3}$ reported by other studies in the US, Taiwan and Singapore (Hewitt and Kok, 1991; Hung and Wang, 2001; Hasson and Paulson, 2003; Venkatachari et al., 2005, 2007; See et al., 2007). This study is one of the first to assess seasonal variations in particulate ROS concentrations and helps delineate the principle factors that influence this pollutant.

\section{The Supplement related to this article is available online at doi:10.5194/acp-14-6777-2014-supplement.}

Acknowledgements. S. S. Khurshid was funded by the National Science Foundation (IGERT Award DGE 0549428), US EPA (STAR Fellowship FP-91747501-0), and Cockrell School of Engineering Thrust Fellowship. We thank M. Grady for collecting solar radiation data at the University of Texas at Austin campus.

Edited by: P. DeCarlo

\section{References}

Arellanes, C., Paulson, S. E., Fine, P. M., and Sioutas, C.: Exceeding of Henry's Law by Hydrogen Peroxide Associated with Urban Aerosols, Environ. Sci. Technol., 40, 4859-4866, 2006.

Ayers, G. P., Penkett, S. A., Gillett, R. W., Bandy, B., Galbally, I. E., Meyer, C. P., Elsworth, C. M., Bentley, S. T., and Forgan, B. W.: Evidence for Photochemical Control of Ozone Concentrations in Unpolluted Marine Air, Nature, 360, 446-449, 1992.

Baulig, A., Poirault, J.-J., Ausset, P., Schins, R., Shi, T., Baralle, D., Dorlhene, P., Meyer, M., Lefevre, R., Baeza-Squiban, A., and Marano, F.: Physicochemical Characteristics and Biological Activities of Seasonal Atmospheric Particulate Matter Sampling in Two Locations of Paris, Environ. Sci. Technol., 38, 5985-5992, 2004.

Bell, M. L., Samet, J. M., and Dominici, F.: Time-Series Studies of Particulate Matter, Annu. Rev. Publ. Health, 25, 247-280, 2004.

Boogaard, H., Janssen, N. A. H., Fischer, P. H., Kos, G. P. A., Weijers, E. P., Cassee, F. R., van der Zee, S. C., de Hartog, J. J., Brunekreef, B., and Hoek, G.: Contrasts in Oxidative Potential and Other Particulate Matter Characteristics Collected Near Major Streets and Background Locations, Environ. Health Persp., 120, 185-191, 2012.

Bowler, R. P. and Crapo, J. D.: Oxidative Stress in Allergic Respiratory Diseases, J. Allergy Clin. Immunol., 110, 349-356, 2002.

Bufalini, J. J., Gay, B. W., and Brubaker, K. L.: Hydrogen Peroxide Formation from Formaldehyde Photooxidation and its Presence in Urban Atmospheres, Environ. Sci. Technol., 9, 816-821, 1972.

Crim, C. and Longmore, W. J.: Sublethal Hydrogen Peroxide Inhibits Alveolar Type II Cell Surfactant Phospholipid Biosynthetic Enzymes, Am. J. Physiol.-Lung C, L129-L135, 1995.

Dollard, G. J. and Davies, T. J.: Observations of $\mathrm{H}_{2} \mathrm{O}_{2}$ and PAN in a Rural Atmosphere, Environ. Pollut., 75, 45-52, 1992.

EPA 40CFR, Part 136 - Guidelines Establishing Test Procedures for the Analysis of Pollutants, Appendix B - Definition and Procedure for the Determination of the Method Detection Limit, Revision 1.11, http://www.gpo.gov/fdsys/pkg/CFR-2011-title40-vol23/pdf/ CFR-2011-title40-vol23-part136-appB.pdf (last access: 2 April 2013), 2011.

Gay, B. W. and Bufalini, J. J.: Hydrogen Peroxide in the Urban Atmosphere, Adv. Chem. Ser., 113, 255-264, 1972.

Geiser, T., Ishigaki, M., van Leer, C., Matthay, M. A., and Broaddus, V. C.: $\mathrm{H}_{2} \mathrm{O}_{2}$ inhibits alveolar epithelial wound repair in vitro by induction of apoptosis, Am. J. Physiol.-Lung C, 287, L448L453, 2004.

Gunz, D. W. and Hoffman, M. R.: Atmospheric Chemistry of Peroxides: A Review, Atmos. Environ., 24, 1601-1633, 1990.

Hasson, A. S. and Paulson, S. E.: An Investigation of the Relationship between Gas-Phase and Aerosol-Borne Hydroperoxides in Urban Air, J. Aerosol Sci., 34, 459-468, 2003.

Heikes, B., Lee, M., Jacob, D., Talbot, R., Bradshaw, J., Singh, H., Blake, D., Anderson, B., Fuelberg, H., and Thompson, A. M.: Ozone, hydroperoxides, oxides of nitrogen, and hydrocarbon budgets in the marine boundary layer over the South Atlantic, J. Geophys. Res., 101, 24221-24234, 1996.

Hewitt, C. N. and Kok, G. L.: Formation and Occurrence of Organic Hydroperoxides in the Troposphere: Laboratory and Field Observations, J. Atmos. Chem., 12, 181-194, 1991.

Holm, B. A., Hudak, B. B., Keicher, L., Cavanaugh, C., Baker, R. R., Hu, P., and Matalon, S.: Mechanisms of $\mathrm{H}_{2} \mathrm{O}_{2}-$ mediated Injury to Type-II Cell Surfactant Metabolism and Protection with PEG-Catalase, Am. J. Physiol., 261, C751-C757, 1991.

Huang, D. M. and Chen, Z. M.: Reinvestigation of the Henry's Law Constant for Hydrogen Peroxide with Temperature and Acidity Variation, J. Environ. Sci-China, 22, 570-574, doi:10.1016/S1001-0742(09)60147-9, 2010.

Huang, M.-F., Lin, W.-L., and Ma, Y.-C.: A Study of Reactive Oxygen Species in Mainstream of Cigarette, Indoor Air, 15, 135-140, 2005.

Hung, H.-F. and Wang, C.-S.: Experimental determination of reactive oxygen species in Taipei aerosols, J. Aerosol Sci., 32, 12011211, 2001.

Hwang, H. and Dasgupta, P. K.: Thermodynamics of the Hydrogen Peroxide-Water System, Environ. Sci. Technol., 19, 255258, 1985.

Jackson, A. V. and Hewitt, C. N.: Atmosphere Hydrogen Peroxide and Organic Hydroperoxides: A Review, Crit. Rev. Env. Sci. Tec., 29, 175-228, 1999. 
Kehrer, J. P.: Free Radicals as Mediators of Tissue Injury and Disease, CRC Cr. Rev. Toxicol., 23, 21-48, 1993.

Khurshid, S. S., Siegel, J. A., and Kinney, K. A.: Indoor Particulate Reactive Oxygen Species Concentrations, Environ. Res., 132, 46-53, 2014.

Kleinman, L. I.: Photochemical formation of peroxides in the Boundary Layer, J. Geophys. Res., 91, 10889-10904, 1986.

Kooy, N. W., Royall, J. A., and Ischiropoulos, H.: Oxidation of 2',7'-Dichlorofluorescin by Peroxynitrite, Free Radical Res., 27, 245-254, 1997.

LaCagnin, L. B., Bowman, L., Ma, J. Y. C., and Miles, P. R.: Metabolic Changes in Alveolar Type II Cells after Exposure to Hydrogen Peroxide, Am. J. Physiol., 259, L57-L65, 1990.

Largiuni, O., Giacomelli, M. C., and Piccardi, G.: Concentration of Peroxides and Formaldehyde in Air and Rain and Gas-Rain Partitioning, J. Atmos. Chem., 41, 1-20, 2002.

Lee, M., Heikes, B. G., and O'Sullivan, D. W.: Hydrogen Peroxide and Organic Hydroperoxide in the Troposphere: A Review, Atmos. Environ., 34, 3475-3494, 2000.

Li, N., Hao, M., Phalen, R. F., Hinds, W. C., and Nel, A. E.: Particulate Air Pollutants and Asthma - A Paradigm for the Role of Oxidative Stress in PM-induced Adverse Health Effects, Cl. Immunol., 109, 250-265, 2003.

Li, N., Xia, T., and Nel, A. E.: The Role of Oxidative Stress in Ambient Particulate Matter-Induced Lung Diseases and Its Implications in the Toxicity of Engineered Nanoparticles, Free Radical Bio. Med., 44, 1689-1699, 2008.

Lind, J. A. and Kok, G. L.: Henry's Law Determinations for Aqueous Solutions of Hydrogen Peroxide, Methylhydroperoxide, and Peroxyacetic Acid, J. Geophys. Res.-Atmos., 99, p. 21119, 1994.

Liu, J., Steinberg, S. M., and Johnson, B. J.: A High Performance Liquid Chromatography Method for Determination of Gas-Phase Hydrogen Peroxide in Ambient Air using Fenton's Chemistry, Chemosphere, 52, 815-823, 2003.

Logan, J. A., Prather, M. J., Wofsy, S. C., and McElroy, M. B.: Tropospheric Chemistry: A Global Perspective, J. Geophys. Res., 86, 7210-7254, 1981.

Morio, L. A., Hooper, K. A., Brittingham, J., Li, T.-H., Gordon, R. E., Turpin, B. J., and Laskin, D. L.: Tissue Injury following Inhalation of Fine Particulate Matter and Hydrogen Peroxide is associated with altered Production of Inflammatory Mediators and Antioxidants by Alveolar Macrophages, Toxicol. Appl. Pharm., 177, 188-199, 2001.

NIST e-Handbook of Statistical Methods, Detection of Outliers, 1.3.5.17, http://www.itl.nist.gov/div898/handbook/ (last access: 1 November 2012), 2010.

Oosting, R. S., Vanbree, L., Vaniwaarden, J. F., Vangolde, L. M. G., and Verhoef, J.: Impairment of Phagocytic Functions of Alveolar Macrophages by Hydrogen Peroxide, Am. J. Physiol., 259, L87L94, 1990.

Pope III, C. A., Burnett, R. T., Thun, M. J., Calle, E. E., Krewski, D., Ito, K., and Thurston, G. D.: Lung Cancer, Cardiopulmonary Mortality, and Long-term Exposure to Fine Particulate Air Pollution, JAMA-J. Am. Med. Assoc., 287, 1132-1141, 2002.

Sakugawa, H., Kaplan, I. R., Tsai, W., and Cohen, Y.: Atmospheric Hydrogen Peroxide, Environ. Sci. Technol., 24, 14521462,1990
Samet, J. M., Dominici, F., Curriero, F. C., Coursac, I., and Zeger, S. L.: Fine Particulate Air Pollution and Mortality in 20 U.Se. Cities, 1987-1994, New Engl. J. Med., 343, 1742-1749, 2000.

Sanders, S. P., Zweier, J. L., Harrison, S. J., Trush, M. A., Rembish, S. J., and Liu, M. C.: Spontaneous Oxygen Radical Production at Sites of Antigen Challenge in Allergic Subjects, Am. J. Resp. Crit. Care, 151, 1725-1733, 1995.

Sarangapani, R. and Wexler, A. S.: The Role of Dispersion in Particle Deposition in Human Airways, Toxicol. Sci., 54, 229-236, 2000.

Schöne, E.: Ueber das atmosphärische Wasserstoffhyperoxyd, Ber. dts. chem. Ges., 7, 1693-1708, 1874.

See, S. W., Wang, Y. H., and Balasubramanian, R.: Contrasting Reactive Oxygen Species and Transition Metal Concentrations in Combustion Aerosols, Environ. Res., 103, 317-324, 2007.

Seinfeld J. H. and Pandis S. N.: Atmospheric Chemistry and Physics: From Air Pollution to Climate Change, 2nd Edn., Wiley Publishers, Hoboken, NJ, 2006.

Shen, H., Barakat, A. I., and Anastasio, C.: Generation of hydrogen peroxide from San Joaquin Valley particles in a cell-free solution, Atmos. Chem. Phys., 11, 753-765, doi:10.5194/acp-11753-2011, 2011.

Singh, H. B., Salas, L. J., and Viezee, W.: Global Distribution of Peroxyacetyl Nitrate, Nature, 321, 588-591, 1986.

Snow, J. A., Heikes, B. G., Shen, H., O’Sullivan, D. W., Fried, A., and Walega, J.: Hydrogen Peroxide, Methyl Hydroperoxide, and Formaldehyde over North America and the North Atlantic, J. Geophys. Res., 112, D12S07, doi:10.1029/2006JD007746, 2007.

Staffelbach, T. A. and Kok, G. L.: Henry Law Constants for Aqueous Solutions of Hydrogen Peroxide and Hydroxymethyl Hydroperoxide, J. Geophys. Res.-Atmos., 98, 12713-12717, doi:10.1029/93JD01022, 1993.

Valavanidis, A., Fiotakis, K., and Vlachogianni, T.: Airborne Particulate Matter and Human Health: Toxicological Assessment and Importance of Size and Composition of Particles for Oxidative Damage and Carcinogenic Mechanisms, J. Environ. Sci. Heal. C, 26, 339-362, 2008.

Venkatachari, P., Hopke, P. K., Grover, B. D., and Eatough, D. J.: Measurement of Particle-Bound Reactive Oxygen Species in Rubidoux Aerosols, J. Atmos. Chem., 50, 49-58, 2005.

Venkatachari, P., Hopke, P. K., Brune, W. H., Ren, X., Lesher, R., Mao, J., and Mitchell, M.: Characterization of Wintertime Reactive Oxygen Species Concentrations in Flushing, New York, Aerosol Sci. Tech., 41, 97-111, 2007.

Vidrio, E., Phuah, C. H., Dillner, A. M., and Anastasio, C.: Generation of Hydroxyl Radicals from Ambient Fine Particles in a Surrogate Lung Fluid Solution, Environ. Sci. Technol., 43, 922 927, 2009.

Wang, Y., Arellanes, C., Curtis, D. B., and Paulson, S. E.: Probing the Source of Hydrogen Peroxide Associated with Coarse Mode Aerosol Particles in Southern California, Environ. Sci. Technol., 44, 4070-4075, 2010.

Walker, S. J., Evans, M. J., Jackson, A. V., Steinbacher, M., Zellweger, C., and McQuaid, J. B.: Processes controlling the concentration of hydroperoxides at Jungfraujoch Observatory, Switzerland, Atmos. Chem. Phys., 6, 5525-5536, doi:10.5194/acp-65525-2006, 2006

Weather Underground, Inc.: www.wunderground.com, last access: 17 December 2013. 
Wexler, A. S. and Sarangapani, R.: Particles do not Increase Vapor Deposition in Human Airways, J. Aerosol. Sci., 29, 197-204, 1998.

Yamada, E., Tomozawa, K., Nakanishi, Y., and Fuse, Y.: Behavior of Hydrogen Peroxide in the Atmosphere and Rainwater in Kyoto, and its Effect on the Oxidation of $\mathrm{SO}_{2}$ in Rainwater, B. Chem. Soc. Jpn., 75, 1385-1391, 2002.
Zhang, X., He, S. Z., Chen, Z. M., Zhao, Y., and Hua, W.: Methyl hydroperoxide $\left(\mathrm{CH}_{3} \mathrm{OOH}\right)$ in urban, suburban and rural atmosphere: ambient concentration, budget, and contribution to the atmospheric oxidizing capacity, Atmos. Chem. Phys., 12, 89518962, doi:10.5194/acp-12-8951-2012, 2012.

Zhu, H., Bannenberg, G. L., Moldeus, P., and Shertzer, H. G.: Oxidation pathways for the intracellular probe 2',7'dichlorofluorescin, Arch. Toxicol., 68, 582-587, 1994. 